\title{
Compression Ratio Effects on Performance, Efficiency, Emissions and Combustion in a Carbureted and PFI Small Engine
}

\author{
William P. Attard, Steven Konidaris, Ferenc Hamori, Elisa Toulson and Harry C. Watson \\ University of Melbourne
}

Copyright $\odot 2007$ SAE International

\begin{abstract}
This paper compares the performance, efficiency, emissions and combustion parameters of a prototype two cylinder $430 \mathrm{~cm}^{3}$ engine which has been tested in a variety of normally aspirated (NA) modes with compression ratio $(\mathrm{CR})$ variations. Experiments were completed using 98-RON pump gasoline with modes defined by alterations to the induction system, which included carburetion and port fuel injection (PFI).

The results from this paper provide some insight into the $\mathrm{CR}$ effects for small NA spark ignition (SI) engines. This information provides future direction for the development of smaller engines as engine downsizing grows in popularity due to rising oil prices and recent carbon dioxide $\left(\mathrm{CO}_{2}\right)$ emission regulations.

Results are displayed in the engine speed, manifold absolute pressure (MAP) and CR domains, with engine speeds exceeding $10000 \mathrm{rev} / \mathrm{min}$ and CRs ranging from 9 to 13. Combustion analysis is also included, allowing mass fraction burn (MFB) comparison. Experimental results showed minimum brake specific fuel consumption (BSFC) or maximum brake thermal efficiency $\left(\eta_{\mathrm{TH}}\right)$ values in the order of $220 \mathrm{~g} / \mathrm{kWh}$ or $37 \%$ could be achieved. A maximum brake mean effective pressure (BMEP) of 13 bar was also recorded at 8000 $\mathrm{rev} / \mathrm{min}$.
\end{abstract}

\section{INTRODUCTION}

In recent times, research into SI engine downsizing has grown in popularity [1-6] as governments begin to limit $\mathrm{CO}_{2}$ emissions and consumers strive for cost savings due to rising oil prices. Thus, manufacturers are trying to improve performance and efficiency while meeting legislative emission standards. One method in achieving manufacturers' goals involves CR variations, either with CR increases in NA modes or intake boosting coupled with CR decreases. Whichever strategy is used, understanding the CR effects in small engines is vital if downsized engines are to be comparable to their larger counterparts.

CR effects have been well documented in larger, lower speed engines [7-10] with larger bore sizes. However, little information exists on small engines of this scale $\left(\sim 400 \mathrm{~cm}^{3}\right)$, particularly modern four valve, pent roof designs. Comparatively, engines found in small passenger vehicles in today's marketplace are usually more than twice the cylinder capacity of the test engine. Hence, whether the previously found performance, efficiency and emissions quantitative results due to $\mathrm{CR}$ variations from larger, lower speed engines hold to small engines of this scale is questioned. Several important differences involving in-cylinder flow, combustion and frictional/temperature affects may be expected as a result of the reduced bore size and increased engine speed.

Carburetion is explored together with PFI as the majority of these small scale engines still operate with the outdated fuel system. This is due to less stringent emission regulations and cost benefits [11-13]. Hence, comparisons are made between modes at varying CRs to quantify the induction effects for these small engines.

\section{OBJECTIVES}

The original intent of this development program was to achieve success in Formula SAE competition. However, from the research and development process, more significant findings concerning small engines have been discovered [4,5,14-17]. This paper provides some insight into the $\mathrm{CR}$ effects, giving direction for future development of small scale engines for passenger vehicles. Specifically, the objectives are to:

> Experimentally explore the effects of CR variations on performance, efficiency and emissions for a small engine across engine speed and MAP domains

> Compare CR effects and combustion operating limits between the small engine and larger cylinder bore engines found in passenger vehicles

> Compare carburetion and PFI fuel delivery systems in a small engine

> Determine combustion parameters for a small high speed engine, comparing the effects of CR and fuel delivery variations across the speed range 


\section{TEST ENGINE}

The downsized test engine used in experiments was specifically designed and developed at the University of Melbourne for use in Formula SAE. The $434 \mathrm{~cm}^{3}$ twin cylinder in-line arrangement featured double overhead camshafts $(\mathrm{DOHC})$ and four valves per cylinder, along with a three speed transmission and dry sump lubrication. Most of the engine components were specially cast or machined from billets. Valve motion and exhaust manifold geometry were held constant over both modes in order for fair comparisons. However, provisions in the piston design allowed for $\mathrm{CR}$ variations. Further general specifications are given in Table 1, with Figure 1 highlighting a sectional view of the engine design.

Table 1: Test engine specifications.

\begin{tabular}{|ll|}
\hline BRAND & UniMelb 'WATTARD' \\
TYPE & $\begin{array}{l}\text { Parallel twin } 4 \text { stroke SI, } \\
\text { Liquid-cooled, } \\
\text { Integral clutch/ transmission }\end{array}$ \\
CAPACITY & $433.8 \mathrm{~cm}^{3}$ \\
BORE x STROKE & $69 \times 58 \mathrm{~mm}$ \\
FIRING ORDER & Unequal $\left(0^{\circ}, 180^{\circ}\right.$ CA) \\
COMPRESSION RATIO & $9-13: 1$ with piston modification \\
COMBUSTION CHAMBER & Pent roof, Central spark plug \\
VALVE ACTUATION & 8 -valve DOHC \\
VALVE TIMING & IVO $24^{\circ}$ BTDC \\
& IVC $72^{\circ}$ ABDC \\
& EVO $57^{\circ}$ BBDC \\
LUBRICATION & EVC $9^{\circ}$ ATDC \\
ENGINE MANAGEMENT & Dry sump \\
TRANSMISSION & Motec M4 EMS \\
\hline
\end{tabular}

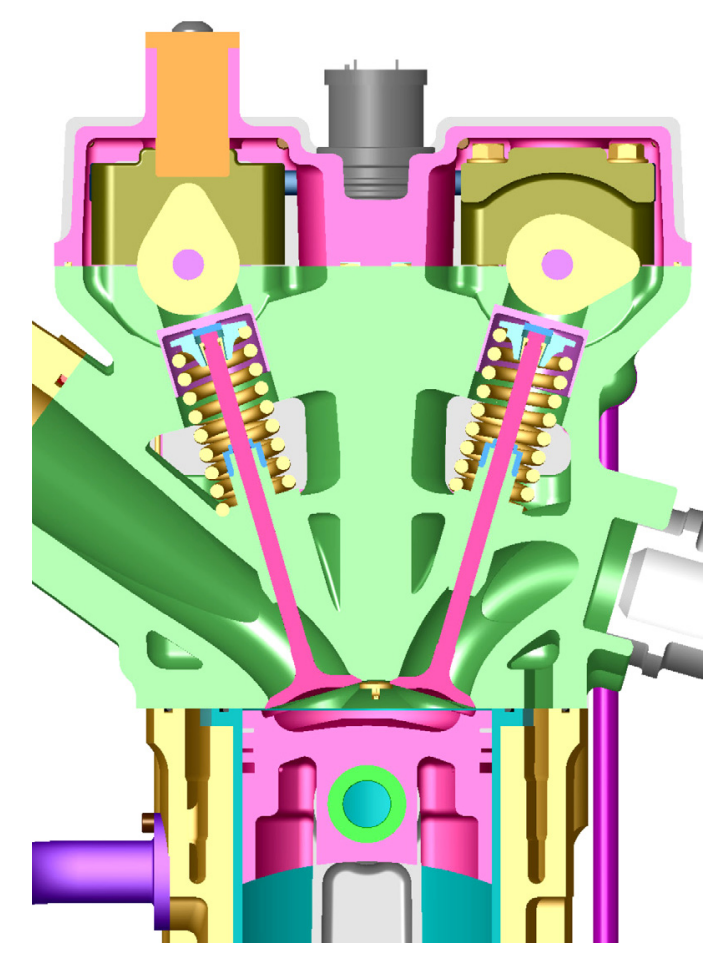

Figure 1: Engine sectional view, highlighting the barrel, cylinder head, piston and piston pin end of the connecting rod.

\section{FUEL AND INDUCTION SYSTEMS}

Experiments were completed using a Shell Optimax 98RON pump gasoline, with specifications previously defined [5]. The use of varying fuel delivery systems necessitated differing intake manifolds between both modes, with images displayed in Figure 2. The OEM carbureted system was fitted with the as supplied OEM intake manifold, meaning the system featured no plenum chamber with both trumpets open to atmosphere. An intake system was manufactured for the PFI mode and featured Nylon 66 intake runners, which were made using the Selective Laser Sintering (SLS) process, together with a fabricated aluminum plenum chamber. Coupling both runners to the plenum chamber enabled the system to be fitted with a $20 \mathrm{~mm}$ diameter intake restriction, which was mandatory by Formula SAE regulation. Further intake system details are given in Table 2, with associated exploded views shown in Appendix A.

Table 2: Specifications defining the fuel delivery and induction systems for the varying test modes.

\begin{tabular}{|c|c|c|}
\hline & \multicolumn{2}{|c|}{ MODE } \\
\hline & (A) NA-CARBS & (B) NA- PFI \\
\hline Fuel Delivery & $\begin{array}{l}1 \text { carb / cylinder, } \\
\text { downdraught, } \\
\text { constant vacuum }\end{array}$ & $\begin{array}{c}1 \text { injector / cylinder, } \\
\text { sequential, } \\
4 \text { orifice nozzle }\end{array}$ \\
\hline Brand & $\begin{array}{l}\text { Mikuni } \\
\text { BDSR36 }\end{array}$ & $\begin{array}{c}\text { Bosch } \\
0-280-156-124\end{array}$ \\
\hline Fuel Pressure & Gravity fed & $500 \mathrm{kPa}$ \\
\hline $\begin{array}{l}\text { Intake Manifold } \\
\text { (Appendix A) }\end{array}$ & $\begin{array}{l}\text { OEM supplied, } \\
\text { SHEET } 12.2\end{array}$ & $\begin{array}{l}\text { Manufactured, } \\
\text { SHEET } 12.3\end{array}$ \\
\hline Intake Restriction & NO & YES (Ø20 mm) \\
\hline Plenum Volume & $N / A$ & 4.5 liters \\
\hline Runner Length & $200 \mathrm{~mm}$ & $350 \mathrm{~mm}$ \\
\hline
\end{tabular}

\section{EXPERIMENTS}

A detailed description regarding the experimental setup has previously been documented [5]. It should be noted that all brake data presented in this paper corresponds to the performance at the gearbox output shaft and not at the crankshaft. This is due to the engine design featuring an integral clutch and transmission within the crankcase. Performance at the crankshaft is expected to be marginally higher, due to the reduction in parasitic losses associated with driving the transmission components.

Testing for each mode commenced at the highest CR, which was limited to 13 . This was the highest achievable with a flat top piston in the pent roof combustion chamber. The decision to use a flat top piston was based on manufacturability, with simple machining processes allowing reductions in CR. Hence, variations ranging from 9-13 were possible through piston crown modifications to a set of custom forged pistons. It is noted that squish areas around the periphery of the chamber were maintained to minimize the differing effects of turbulence and resulting combustion effects for varying CRs. 


\section{(A) NA - CARBS}
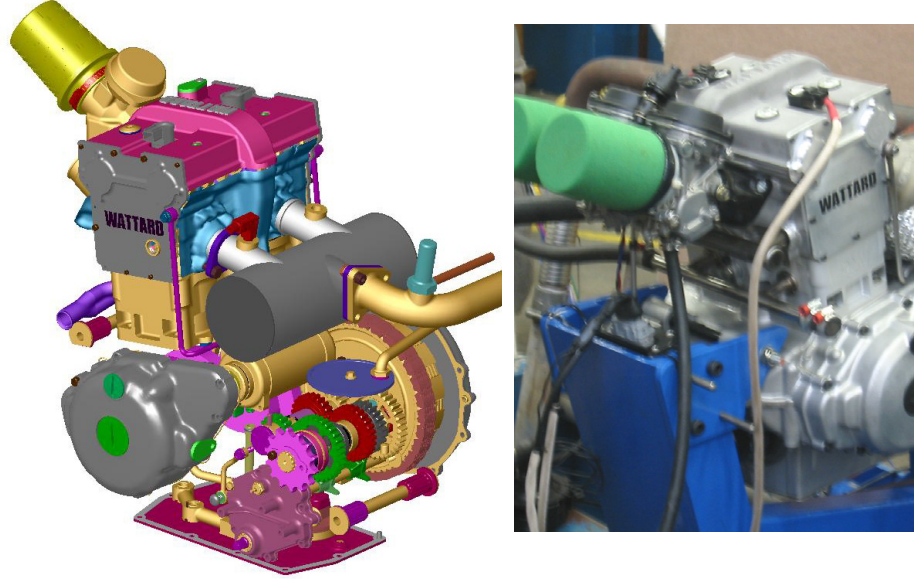

(B) NA - PFI
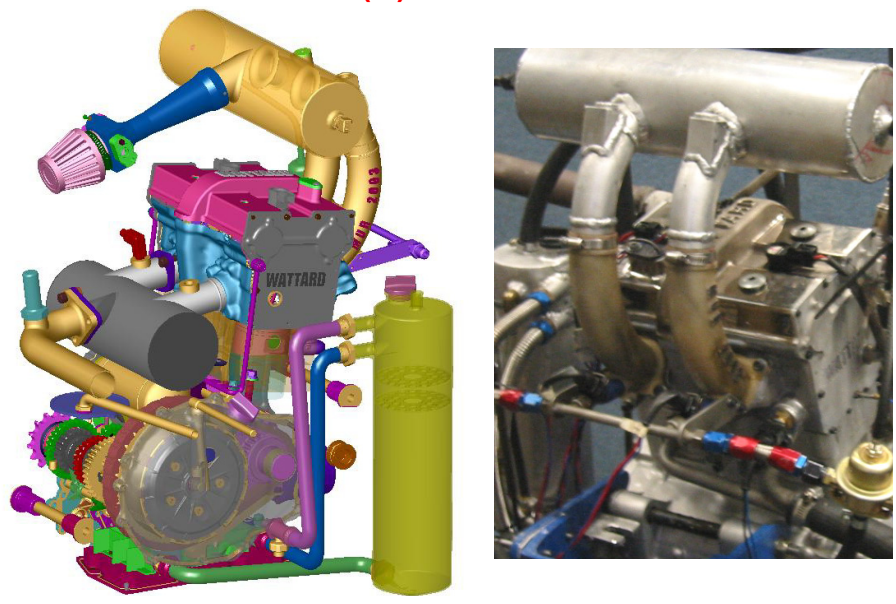

Figure 2: Fuel delivery modes used in experiments, (Upper): Mode A - NA with carburetion (Lower): Mode B - NA with PFI.

The ignition tuning strategy involved finding the minimum spark advance for maximum brake torque (MBT-ST) or in the case when ignition timing was knock limited, the knock limited spark timing (KL-ST). The first stage of knock control relied on traditional methods involving varying degrees of spark retard and/or fuel enrichment [18], albeit with the penalty of increased fuel consumption.

The fuel tuning strategy varied as the original intended Formula application did not govern specific emissions. Hence, lambda $(\lambda)$ varied depending on the load condition as stoichiometric air-fuel ratio (AFR) for threeway catalyst (TWC) operation was not required. Lean and stoichiometric mixtures were targeted at light and medium loads to improve efficiency and reduce fuel consumption. Richer mixtures were used at near full load conditions associated with achieving maximum brake performance. This improved brake output and provided component protection due to the reduced combustion temperatures. Further details outlining the tuning strategy are given in Table 3 .
Table 3: Engine tuning strategy applied to carburetion and PFI modes over the varying test conditions.

\begin{tabular}{|c|c|c|c|}
\cline { 2 - 4 } \multicolumn{1}{c|}{} & \multicolumn{3}{c|}{ LOAD CONDITION } \\
\cline { 2 - 4 } \multicolumn{1}{c|}{} & Light & Medium & Heavy \\
\hline BMEP (kPa) & $<300$ & $300-600$ & $>600$ \\
\hline Targeted $\lambda$ & $1.1-1.2$ & 1 & 0.9 \\
\hline Spark Timing & MBT & MBT & MBT or KL \\
\hline PFI Injection Timing & MBT & MBT & MBT \\
\hline
\end{tabular}

\section{KNOCK LIMITS}

The knock (KL) and damage limit (DL), previously published by Rothe [19], were used to quantify knock limits to ensure engine reliability, with the knock amplitude (KA) defined as the zero to peak pressure of the high pass filtered cylinder pressure.

$$
\begin{aligned}
& >\mathrm{KL} \quad 1 \% \text { cycles with } \mathrm{KA}>4 \text { bar } \\
& >\mathrm{DL} \quad 1 \% \text { cycles with } \mathrm{KA}>20 \text { bar }
\end{aligned}
$$

Figure 4 displays the knock limitations as functions of engine speed, MAP and CR. The cross plots have been constructed from experimental data points, which include CRs of 9.6, 10, 11 and 13. Resulting piston crown and combustion chamber shapes associated with each CR are displayed in Figure 3. The cross hatched areas in Figure 4 indicate domains where engine operation was $\mathrm{KL}$ but could be controlled via tuning strategies to avoid the DL. The performance limit (PL), highlighted by the dashed line corresponds to each modes wide open throttle (WOT) condition for a given CR. Thus, for each mode, cross plots of engine speed versus MAP and $C R$ versus engine speed all share a common PL line in dimensional space.

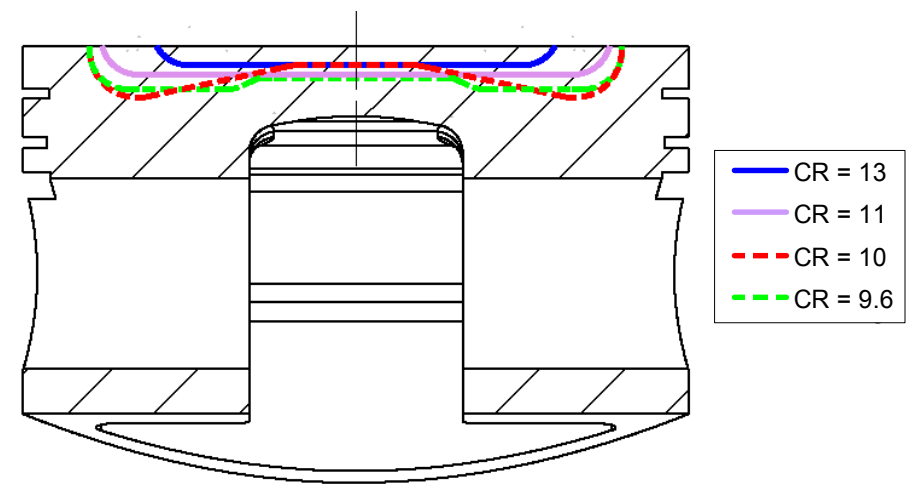

Figure 3: Piston sectional view illustrating the combustion chamber geometry for varying CRs. Symmetrical about the piston central axis.

Figure 4 displays the PFI knock limited regions. However, the carburetion knock limits were not reached over the test CR range, which was limited by the piston design. Furthermore, the carbureted system featured differing intake system geometry with shorter intake runners when compared to PFI (Table 2). Thus, peak BMEP values occurred at higher engine speeds where 
knock is less susceptible [4,5,19-21]. Trends from the PFI knock limits outlined in Figure 4 also confirm that for a given CR and MAP condition, knock is less susceptible at higher speeds. The reduced knock likelihood is a consequence of the increased flame speeds within the combustion chamber, which consume the unburnt mass in the end-gas region more quickly. Increasing flame speeds decreases the likelihood of knock due to the reduced end-gas residence time within the combustion chamber. This will be documented later in this paper.

In the NA-PFI mode, knock levels above the DL were observed in the $6000 \mathrm{rev} / \mathrm{min}$ region at the highest achievable CR of 13. Hence, knock control was achieved with reductions in spark timing while keeping fuel mixtures constant. Experiments also found that spark retard and/or fuel enrichment can be used as methods of knock control for up to 1-2 CR points, depending on the knock severity $[4,5,15]$.

When comparing the knock limits of Figure 4 to modern, larger bore automobile engines with similar combustion chambers [22-26], small engines allow further increases in CR before exceeding the DL. Increases in CR can produce performance, efficiency and emission benefits, associated with brake output increases and BSFC- $\mathrm{CO}_{2}$ reductions. With pump gasoline, results showed the potential for engine operation at a CR exceeding 13, compared to $\mathrm{CR}$ values near 10 for typical larger bore automobile engines.

\section{(A) NA - CARBS}
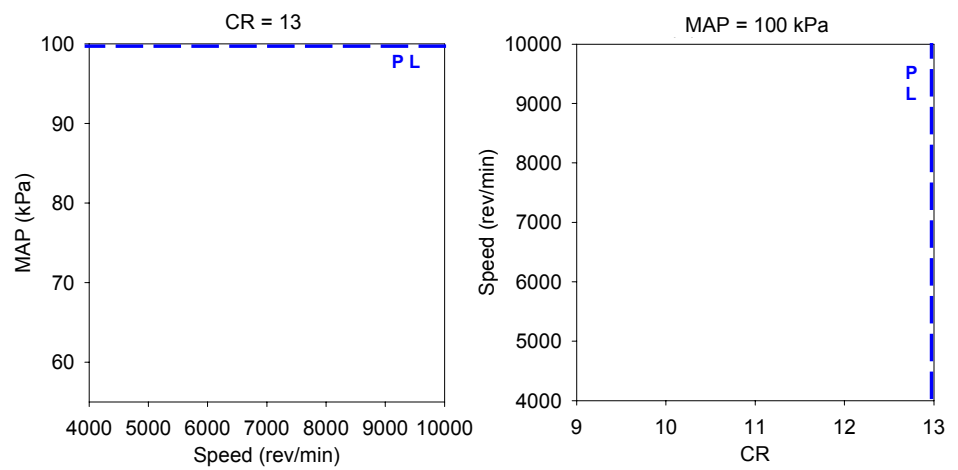

(B) NA - PFI
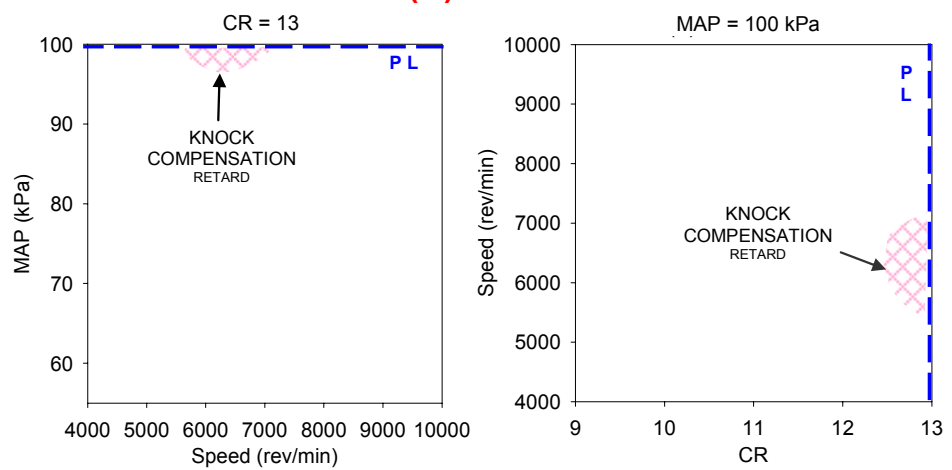

Figure 4: Knock limitations versus engine speed, MAP and $\mathrm{CR}$. Cross hatched areas indicate operation with spark retard and/or fuel enrichment to compensate for knock. PL is the performance limit line defined at each modes WOT for a given CR.
Further increases in small engine CR are achievable using modern knock preventative strategies. These strategies could include direct injection (DI), exhaust gas recirculation (EGR), intake charge cooling and/or variable valve timing (VVT) [1,7,18,27-29]. However, these strategies were not implemented during experiments due to their added complexity and well documented effects.

The high CR achieved for this particular small engine when compared to larger units is attributed to the physical size reduction, particularly the reduced bore diameter and fast burn combustion chamber. This results in engine speed increases together with end-gas volume reductions around the periphery of the chamber, allowing $\mathrm{CR}$ and/or MAP values to be increased before exceeding the DL. This has major benefits in extending the operating limits in downsized applications [1-5,2831].

\section{EXPERIMENTAL RESULTS}

Contour plots are used to display the large quantities of performance, efficiency and emissions experimental results. Results are presented in brake format with varying engine speed, MAP and CR parameters. The contour plot data is presented across two domains as follows:

- Engine speed versus MAP at the highest achievable CR

- $C R$ versus engine speed at the highest achievable MAP

This allows trends to be established and visualized to quantify parameter variation effects. Moreover, plots also allow comparison to larger bore engines to quantify any performance, efficiency or emission effects attributed to the reduced cylinder capacity. These effects are summarized in Table 4, which compares the test engine's experimental results to published data for modern, larger bore engines found in passenger vehicles $[4,7,8,22,23,25]$.

Table 4: Comparing the performance, efficiency and emissions of the test engine with typical larger bore engines found in passenger vehicles.

\begin{tabular}{|l|c|c|}
\cline { 2 - 3 } \multicolumn{1}{c|}{} & Test Engine & $\begin{array}{c}\text { Typical Larger } \\
\text { Bore Engine }\end{array}$ \\
\hline Cylinder Capacity & $217 \mathrm{~cm}^{3}$ & $400-650 \mathrm{~cm}^{3}$ \\
\hline Bore Diameter & $69 \mathrm{~mm}$ & $85-95 \mathrm{~mm}$ \\
\hline Fuel Delivery & Carburetion, PFI & $\mathrm{PFI}$ \\
\hline CR & 13 & $9.5-10.5$ \\
\hline Maximum BMEP & $1260 \mathrm{kPa}$ & $1000-1100 \mathrm{kPa}$ \\
\hline Maximum $\eta_{\mathrm{TH}}$ & $37 \%$ & $32-34 \%$ \\
\hline Maximum $\eta_{\mathrm{NOL}}$ & $108 \%$ & $95-105 \%$ \\
\hline Minimum $\mathrm{BSCO}_{2}$ & $730 \mathrm{~g} / \mathrm{kWh}$ & $800-850 \mathrm{~g} / \mathrm{kWh}$ \\
\hline
\end{tabular}




\section{Performance:}

\section{BRAKE MEAN EFFECTIVE PRESSURE (BMEP)}

Figure 5 displays BMEP contours for both carbureted and PFI modes. When compared to larger bore engines, trends show matching BMEP effects for varying MAP and CR [7-10,32-37]. Increases in BMEP are shown to be directly proportional to increases in MAP for all speeds, primarily due to increases in air consumption and $\eta_{\mathrm{TH}}$.

Increases in $\mathrm{CR}$ are shown to directly correlate to increases in BMEP for all speeds. The increases in BMEP are attributed to a combination of both increased air consumption and improved combustion. As the CR is increased, the residual gas fraction within the cylinder decreases. Reducing the hot products within the cylinder minimizes the warm up of the incoming charge during the induction process, improving charge density and air consumption. A bulk increase in charge density also enhances the combustion process with improved burning rates. A BMEP improvement in the order of 10$13 \%$ was recorded across both carburetion and PFI with a CR increase from 10 to 13 . These values closely correspond to experimental results recorded in larger bore engines together with fuel-air cycle analysis [7-10]. However, further performance improvements associated with $\mathrm{CR}$ increases are primarily limited by knock together with piston crown geometry constraints as previously outlined.

At the highest test $C R$ of 13 , peak BMEP values in the region of $1200-1300 \mathrm{kPa}$ were recorded at mid range speeds. These small engine values are compared to larger bore OEM engines fitted to passenger vehicles as outlined in Table 4, which achieve in the order of 1000$1100 \mathrm{kPa}$ BMEP $[22,23,36,37]$. The BMEP performance discrepancies are largely associated with the CR differences associated with the differing bore sizes and engine speeds, further highlighting the performance potential for small cylinder engines.

\section{SPARK TIMING}

All spark timing data points displayed in Figure 6 are recorded in accordance with the tuning strategy (Table 3 ) to ensure a compromise between performance and efficiency, while maintaining engine reliability. Trends from Figure 6 show that as the speed increases, the spark timing must be advanced to maintain MBT-ST since the combustion burn duration in crank angle (CA) degrees increases. Reductions in spark advance values as the MAP and/or CR increase are results of decreases in burn duration. Decreases in burn duration are caused by increased flame speeds, as turbulence levels increase and charge density within the cylinder improves as a result of the reduced residual gas content. Spark timings over the test domain for both modes are higher relative to larger bore engines [26,36]. However, spark timing trends for parameter variation closely follow the literature $[7,8]$.

\section{(A) NA - CARBS}
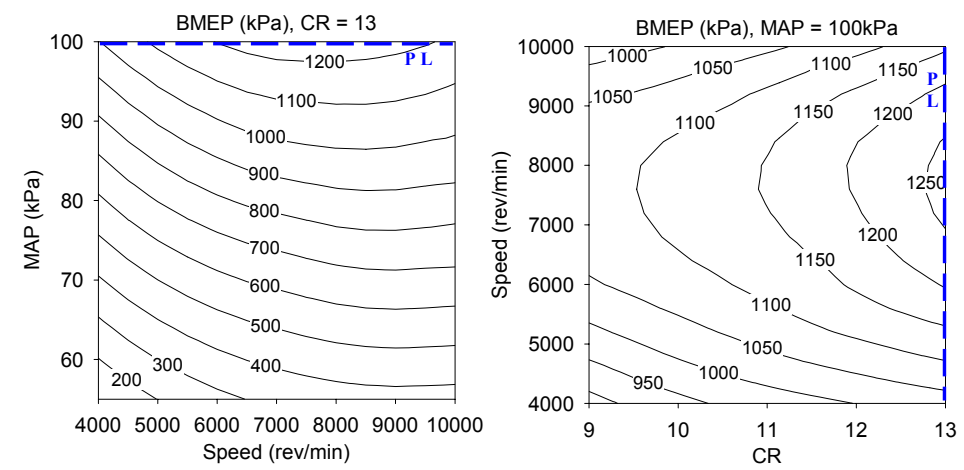

(B) NA - PFI
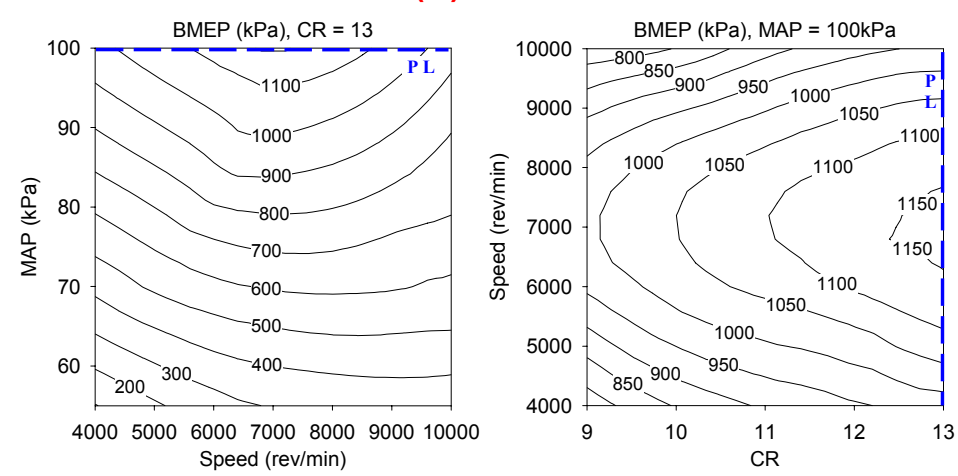

Figure 5: BMEP trends versus engine speed, MAP and $C R$. (Left): $C R=13$, (Right): MAP $=100 \mathrm{kPa}$. PL is the performance limit line defined at WOT for a given CR.

\section{(A) NA - CARBS}
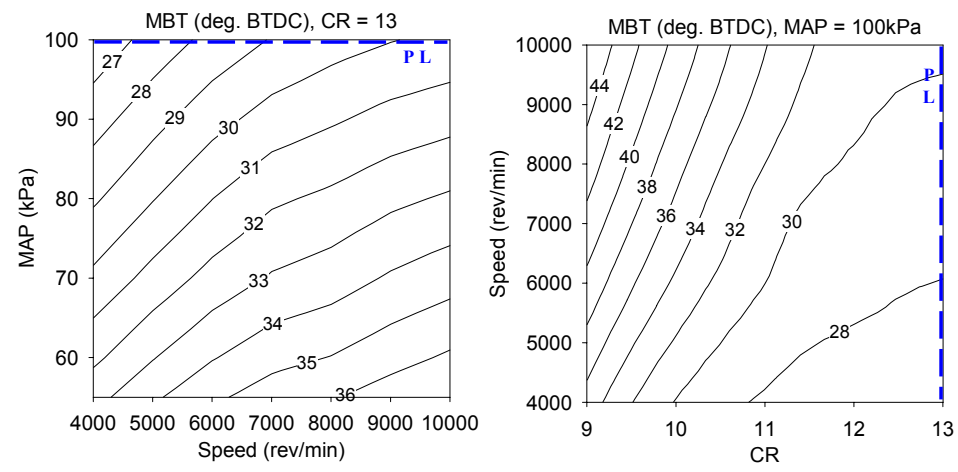

(B) NA - PFI
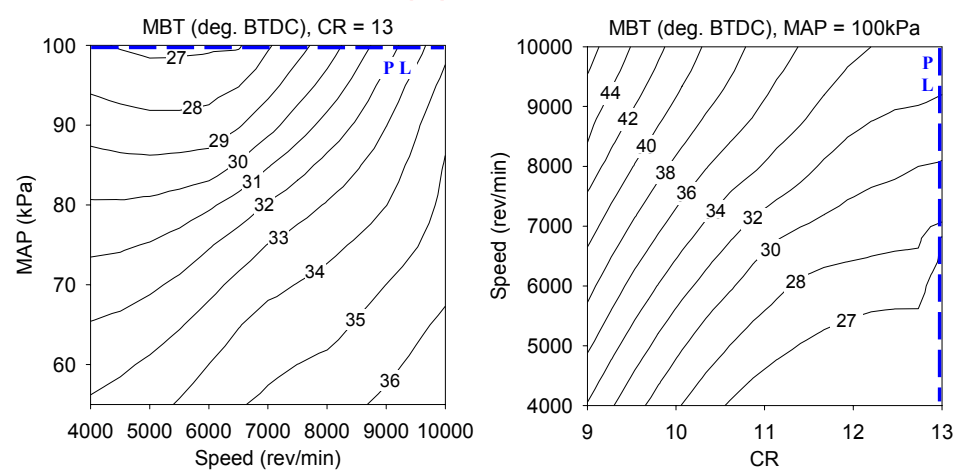

Figure 6: Spark timing trends versus engine speed, MAP and CR. (Left): $C R=13$, (Right): $M A P=100 \mathrm{kPa}$. $\mathrm{PL}$ is the performance limit line defined at WOT for a given $\mathrm{CR}$. 
Spark timing variations between small and large cylinder engines are primarily caused by different operating speed ranges associated with the varying bore size and bore/stroke ratio. Furthermore, smaller bore engines generally operate with little, if any spark retard for knock compensation, due to the reduced propensity for knock to occur. This is highlighted by a modern larger bore engine requiring a $\mathrm{KL}-\mathrm{ST}$ of $5^{\circ}$ BTDC at low engine speeds (2000 rev/min) to ensure engine reliability, which subsequently compromised efficiency [26].

\section{Efficiency:}

\section{VOLUMETRIC EFFICIENCY ( $\left.\eta_{\text {VOL }}\right)$}

As can be seen from Figure 7, volumetric efficiency $\left(\eta_{\mathrm{NOL}}\right)$ increases are caused primarily by the rising MAP for a given engine speed. However, trends from CR variation show minor increases in $\eta_{\mathrm{NOL}}$ as the $\mathrm{CR}$ is increased from 9 to 13 . The improved cylinder filling is caused by the reduced heating effect from the lower residual gas fraction, which increases the trapped charge density. This change in $\eta_{\mathrm{VO}}$ is only minor, with a $1-3 \%$ variation corresponding to a $50 \%$ decrease in the residual gas fraction over the test $C R$ range.

Trends from both modes suggest that for a MAP above $80 \mathrm{kPa}$, air consumption rates are highly dependent on intake manifold resonant waves, which increase in intensity to become most dominant at WOT. This resonant wave, when correctly timed in the induction process, improves air consumption and reduces the residual gas fraction within the cylinder [38]. With resonant tuning, peak $\eta_{\text {VOL }}$ values near $100 \%$ have been achieved for both modes. These values are similar to larger bore engines $[7,8,36]$ as outlined in Table 4 . However, these values are attained at higher engine speeds where knock is less susceptible. It is also noted that these values were achieved with narrow valve overlap $\left(33^{\circ}\right)$, similar to production based passenger vehicle engines [39]. This provided adequate through scavenging but avoided excessive airflow losses.

\section{BRAKE SPECIFIC FUEL CONSUMPTION (BSFC) and BRAKE THERMAL EFFICIENCY $\left(\eta_{\mathrm{TH}}\right)$}

Both the BSFC and $\eta_{\mathrm{TH}}$ contours are displayed in Figure 8. For both carburetion and PFI modes, peak $\eta_{\mathrm{TH}}$ occurred in the $80-90 \mathrm{kPa}$ MAP, 5000-6000 rev/min (10 $\mathrm{m} / \mathrm{s}$ mean piston speed) region as a result of high mechanical efficiency, low pumping losses and fuel mixtures which were nearer to stoichiometric. Peak efficiency values are compared at similar $\lambda$ with carburetion achieving $33 \%$ and PFI $34 \%$. BSFC trends due to $C R$ changes show efficiency improvements for increasing CRs. Increases of the order of $13 \%$ in relative efficiency can be achieved by increasing the CR from 9 to 13 across all speeds at WOT. These results correlate to previous published data for larger bore engines [7,8,32-35]. These results contribute to the majority of BMEP performance improvement associated with the $C R$ increases of Figure 5.
(A) NA - CARBS
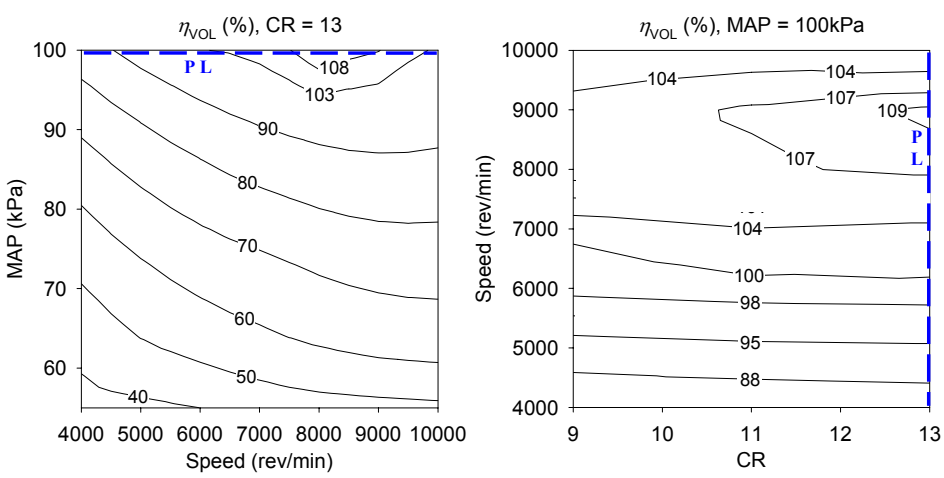

(B) NA - PFI
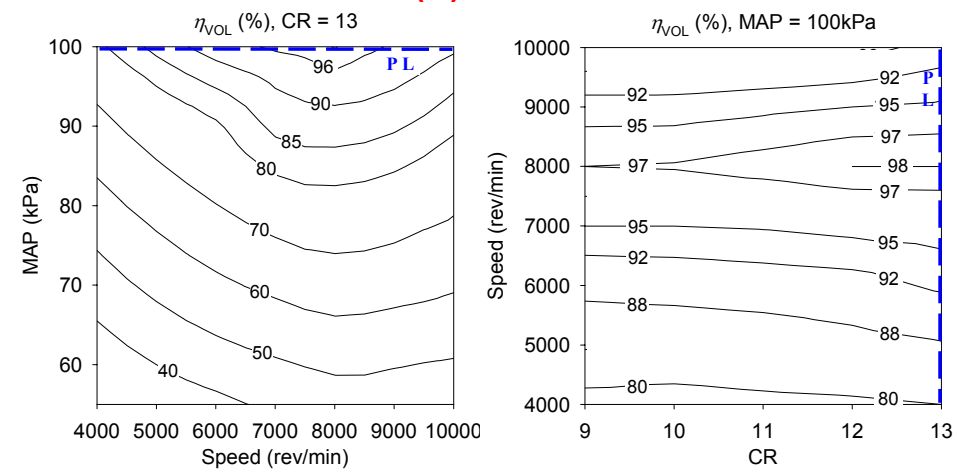

Figure 7: $\eta_{\text {VOL }}$ trends versus engine speed, MAP and CR. (Left): $C R=13$, (Right): $M A P=100 \mathrm{kPa}$. $\mathrm{PL}$ is the performance limit line defined at WOT for a given $\mathrm{CR}$.

\section{(A) NA - CARBS}
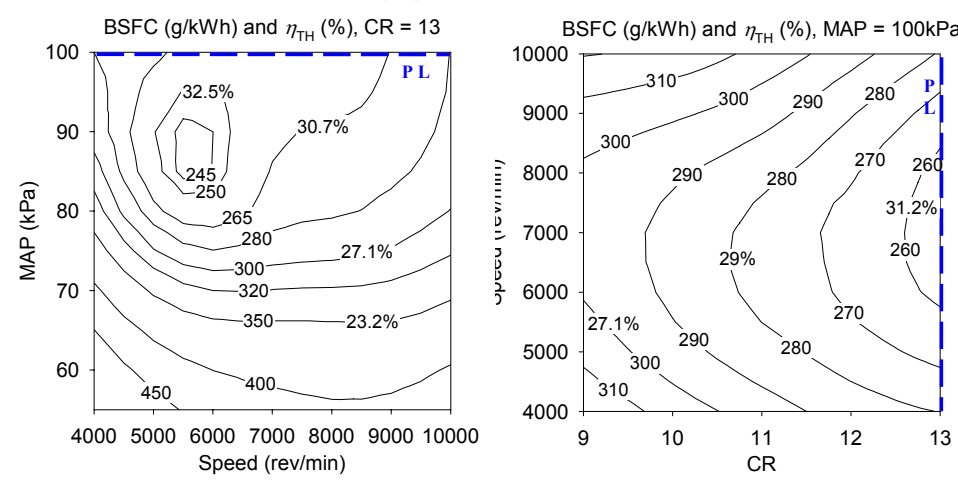

(B) NA - PFI
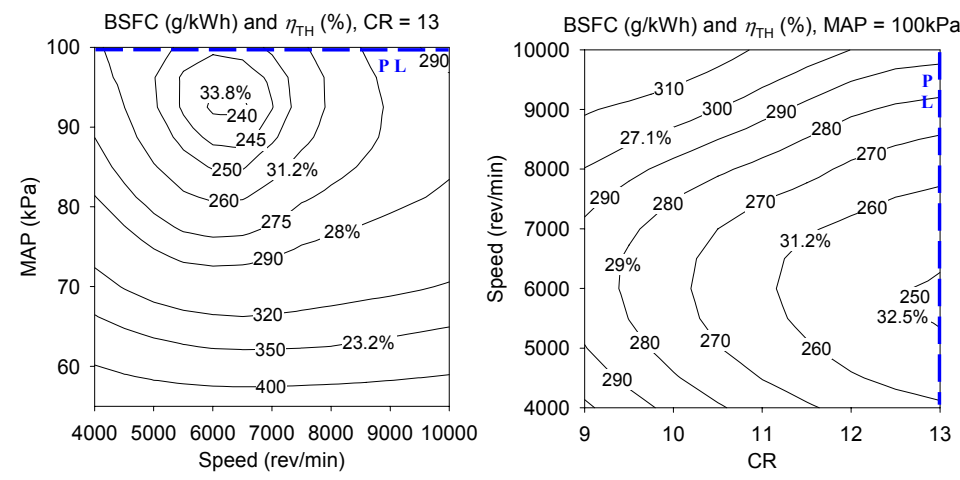

Figure 8: $\mathrm{BSFC}$ and $\eta_{\mathrm{TH}}$ trends versus engine speed, MAP and CR. (Left): CR = 13, (Right): $M A P=100 \mathrm{kPa}$. $\mathrm{PL}$ is the performance limit line defined at WOT for a given $C R$. 
Figure 9 displays BSFC and $\eta_{\mathrm{TH}}$ contours corrected to stoichiometric fuel conditions to allow efficiency comparisons to other engines irrespective of the fuel mixture. The correction procedure is outlined in Attard [4]. A corrected peak brake $\eta_{\mathrm{TH}}$ of $37 \%$ was calculated with PFI at the highest test CR of 13. A $3 \%$ lower $\eta_{\mathrm{TH}}$ is also observed for carburetion, likely due to the poor mixture homogeneity due to reduced atomization and fuel breakup. These efficiency results are slightly higher than those found in similar small engines [40], with the improved efficiency associated with enhanced combustion and high mechanical efficiency. These contributing factors allowed the engine package to achieve comparatively high BMEP values $[4,14,15,40,41]$. It is also recognized that further potential exists for improved BSFC and $\eta_{\mathrm{TH}}$ using well documented methods such as EGR, lean operation and DI $[1,2,7,8,42]$.

Peak $\eta_{\mathrm{TH}}$ values are also compared to modern, larger bore automobile engines operating at stoichiometric conditions, as outlined in Table 4. Generally, typical peak efficiency values for modern automobile engines range between $32-34 \%[4,7,8,22,23,25]$. Smaller bore engines inherently suffer from increased heat losses when compared to larger engines due to the higher surface-to-volume ratio [13], which results in reducing small engine efficiencies. However, the test engine's improved efficiency is attributed to the extension of the $\mathrm{KL}$ due to the reduced bore size and fast burn combustion chamber. This allowed for CR increases, which offset the higher heat losses.

\section{Emissions:}

It is noted that governments regulate emission control in terms of vehicle measured tailpipe emissions relative to distance traveled [43]. Hence, small engines fitted to small vehicles require reduced after treatment clean-up to satisfy emission standards. Nevertheless, engine out brake specific emission results are presented to allow comparisons between modes and other engines, irrespective of vehicle and emission treatment strategies. For comparative purposes, individual cylinder emissions data from experiments has been corrected to stoichiometric conditions. The correction process with raw results are documented [4].

\section{BRAKE SPECIFIC HYDROCARBONS (BSHC)}

Figure 10 displays corrected brake specific hydrocarbon (BSHC) results from steady state testing. Trends show that the PFI system has clear advantages in reducing hydrocarbon $(\mathrm{HC})$ emissions when compared to carburetion for optimized injection timings, with significant $\mathrm{HC}$ reductions recorded across the test domain. This is due to the improved fuel break-up and atomization which helps vaporize the liquid fuel. This minimizes the wall wetting and pooling along the length of the inlet tract $[7,13,17,44]$.
(A) NA - CARBS
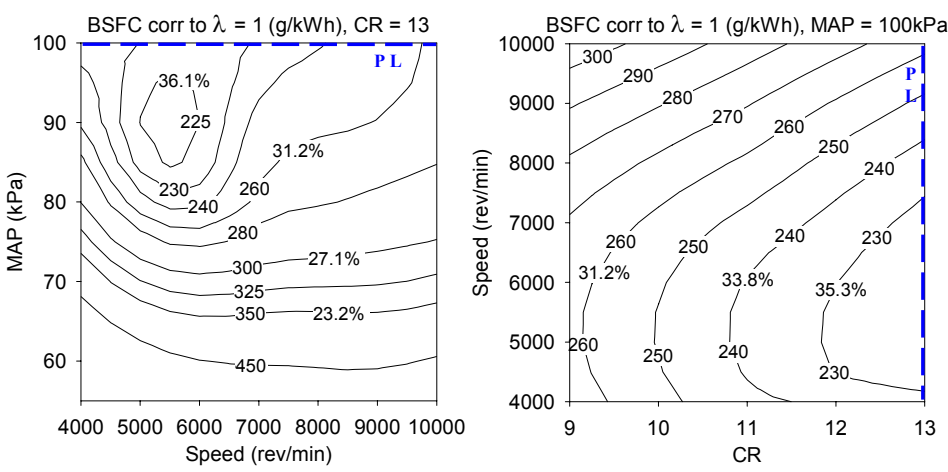

(B) NA - PFI
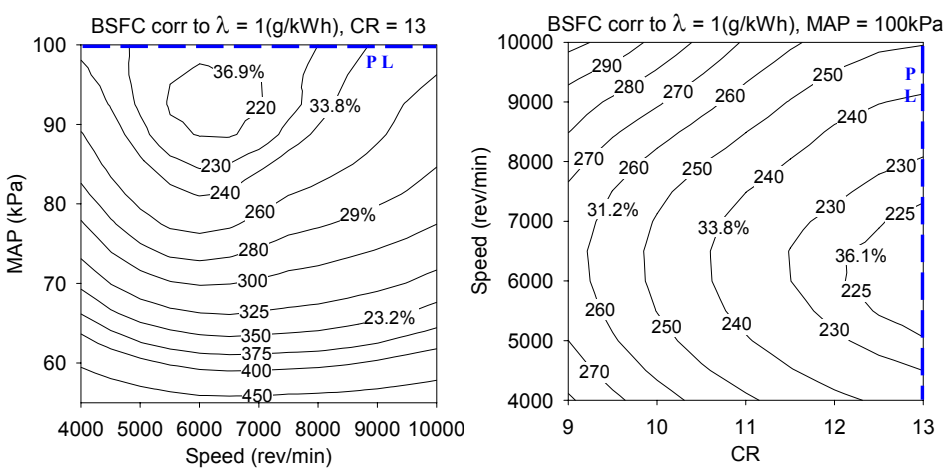

Figure 9: Corrected BSFC and $\eta_{\mathrm{TH}}$ trends $(\lambda=1)$ versus engine speed, MAP and CR. (Left): CR = 13, (Right): MAP = $100 \mathrm{kPa}$. $\mathrm{PL}$ is the performance limit line defined at WOT for a given $\mathrm{CR}$.

\section{(A) NA - CARBS}
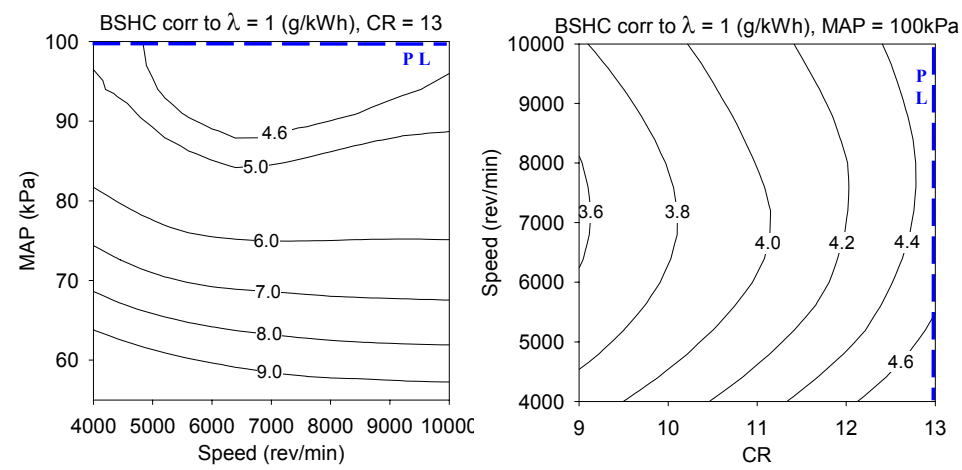

(B) NA - PFI
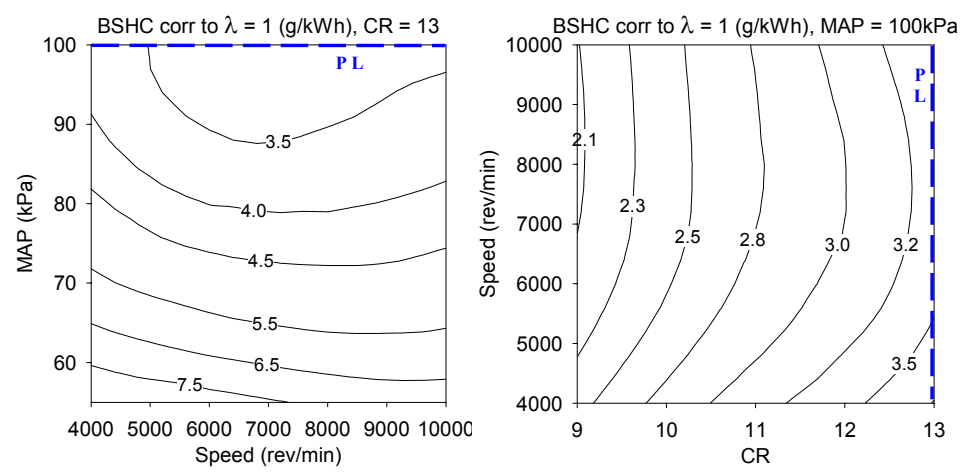

Figure 10: Corrected BSHC trends versus engine speed, MAP and CR. (Left): $C R=13$, (Right): $M A P=100 \mathrm{kPa}$. PL is the performance limit line defined at WOT for a given CR. 
PFI HC reductions are more obvious at part load due to the reduced airflow and absence of resonant waves in the inlet tract, which tend to break-up the larger fuel droplets associated with carburetion. This validates published data [44] and is one of several reasons for the universal adoption of PFI in larger engines. PFI use in small engines is not as prominent due to less stringent emission regulations among other factors.

Trends from Figure 10 show increases in BSHC emissions with CR increases across all speeds. This is due to varying surface-to-volume ratios and the increased importance of crevice volume effects at high $\mathrm{CR}$. These increasing $\mathrm{HC}$ effects are difficult to avoid due to more of the premixed charge being forced into the crevices as the CR increases. As the engine speed increases for fixed MAP values, corrected contours show decreasing $\mathrm{HC}$ trends due to increasing wall temperatures and changes in the in-cylinder and exhaust oxidation rate. Increasing wall temperatures due to increasing combustion temperatures at high mean piston speeds increases the heat flux and hence reduces $\mathrm{HC}$ emissions. This offsets the reduced burn up times at high engine speeds. The effectiveness of unburned hydrocarbon oxidation is significantly enhanced with speed increases as the expansion stroke and exhaust gas temperatures substantially increase [7]. As load or MAP increases for constant speed, HC concentrations decrease for similar reasons. Therefore, specific $\mathrm{HC}$ emissions are shown to decrease as power is increased for all conditions across both modes.

Experimental results show higher $\mathrm{HC}$ levels when compared to larger bore modern automobile engines. $\mathrm{HC}$ emissions of small bore engines are generally higher due to the increased surface-to-volume ratio and higher $\mathrm{CR}$ [13]. However, the $\mathrm{HC}$ effects due to parameter variation from experiments closely follow the literature $[7,8]$. Moreover, engine out BSHC levels for this particular engine are lower than previously published $\mathrm{HC}$ data for modern small and older larger bore engines $[12,36,46]$. The differences between other small engines with similar surface-to-volume ratios are explained by a number of factors, but mainly attributed to the engine design. The engine design featured minimal crevice volume together with a gasketless interface [16]. The gasketless interface provided a more even temperature distribution across the cylinder block and head, which reduced HC levels [16]. When compared to older larger bore engines, the increased surface-to-volume ratio and higher CR of the test engine are offset by the significantly reduced crevice volume, mainly attributed to the piston top land thickness.

\section{BRAKE SPECIFIC CARBON DIOXIDE $\left(\mathrm{BSCO}_{2}\right)$}

Figure 11 displays brake specific carbon dioxide $\left(\mathrm{BSCO}_{2}\right)$ results. The $\mathrm{BSCO}_{2}$ effects resulting from MAP, speed and CR variations directly correlate to the efficiency trends previously outlined in Figure 9. Hence, the merging contour lines show efficiency to be directly proportional to $\mathrm{BSCO}_{2}$ with improvements in fuel efficiency corresponding to reduced $\mathrm{CO}_{2}$ emissions. In both modes, a $\mathrm{CO}_{2}$ reduction in the order of $13 \%$ is achieved by increasing the CR from 9 to 13, which also corresponds to previous $\eta_{\mathrm{TH}}$ improvements. When compared to larger bore automobile engines, as outlined in Table $4, \mathrm{BSCO}_{2}$ benefits are evident due to the improved efficiencies associated with the test engine.

\section{(A) NA - CARBS}
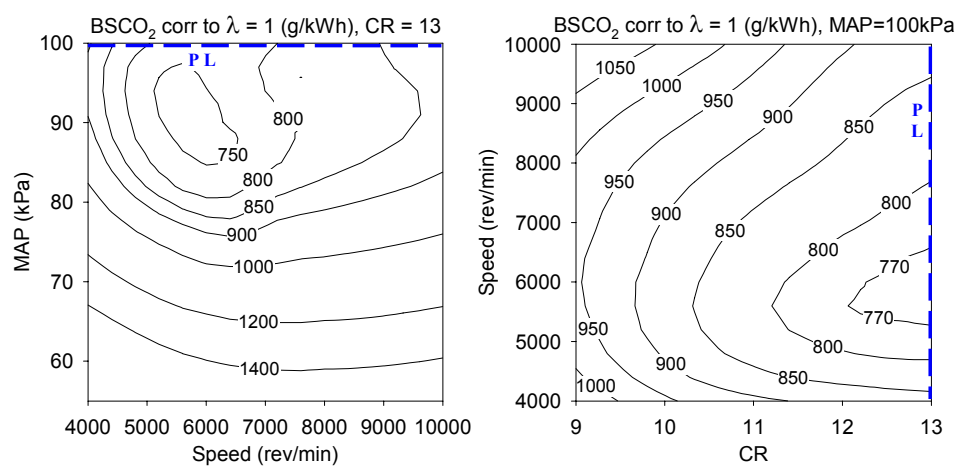

(B) NA - PFI
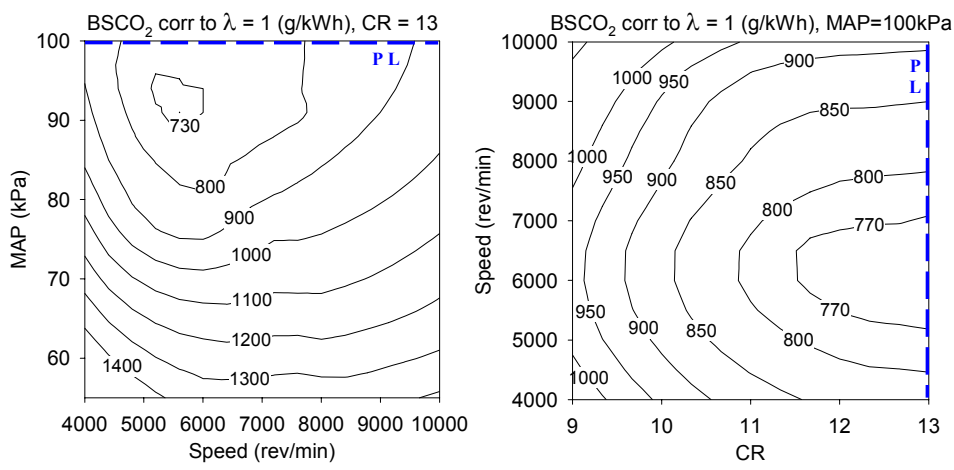

Figure 11: Corrected $\mathrm{BSCO}_{2}$ trends versus engine speed, MAP and CR. (Left): CR $=13$, (Right): $M A P=100 \mathrm{kPa}$. $\mathrm{PL}$ is the performance limit line defined at WOT for a given CR.

\section{PERFORMANCE, EFFICIENCY AND EMISSION COMPARISONS}

Figure 12 displays $\mathrm{CR}$ and mode comparisons at WOT (100 kPa MAP) to evaluate the performance, efficiency and emission effects. Only three data sets are presented in graphs across the test range. However, results provide the reader with clear findings from the experiments presented in this paper.

The performance comparisons (Figure 12-Upper) for equal CRs suggest similar BMEP potential between PFI and carburetion when accounting for the airflow discrepancies, which could be eliminated with intake system optimization [4,5,17]. The reduced air consumption of the PFI system is associated with fitting the mandatory Formula SAE intake restriction. Although engine air consumption rates were not high enough to cause restrictor choking, the intermittent pulsing attributed to the uneven firing order limited instantaneous peak airflow through the nozzle, resulting in reduced performance $[4,5,17]$. 
The fuel efficiency comparisons (Figure 12-Middle) indicate clear gains when implementing PFI over carburetion. The improved fuel break-up and atomization of the PFI system aids in vaporization, resulting in improved mixing together with minimal wall wetting and pooling. These effects improve efficiency and magnify in affect at low engine speed and load conditions (Figure 9). It is also reiterated that these results are attained from steady state testing, with transient testing yielding significantly different results due to fuel control and pooling issues associated with the high fuel entry position of carburetion. Hence, efficient TWC operation for emission control is difficult to achieve with this system.

When comparing emissions between carburetion and $\mathrm{PFI}$ (Figure 12-Lower), $\mathrm{HC}$ emissions standout as being the major difference between the two modes of fuel delivery. Reductions in the order of $20 \%$ are shown at WOT when implementing PFI during steady state testing, with $\mathrm{HC}$ differences between both modes expected to increase during transient operation. The differing fuel efficiencies between carburetion and PFI are shown to have insignificant affects on combustion (Figure 13), consistent with the similar performance potential findings discussed. However, the poorer $\eta_{\mathrm{TH}}$ of the carbureted system has resulted in increased levels of engine out unburnt $\mathrm{HC}$ emissions. These performance, efficiency and emission results confirm previous findings from larger bore engines, with PFI generally adopted over carburetion due to improved fuel and emission control $[7,13,44]$.

\section{COMBUSTION PARAMETERS}

Currently, the manner in which combustion occurs in small cylinder, high speed engines is largely unknown. However, combustion has been found to be the main limitation in extending the operating limits for downsized applications [4,5]. Several important differences may be expected as a result of the smaller capacity and increased engine speed when compared to larger bore engines. These include:

$>$ Increase in wall effects on tumble and swirl dissipation

$>$ Change in squish velocities from reduced squish areas

$>$ Reduction in the turbulent length scale

$>$ Increased heat losses from the increased surface to volume ratio

$>$ Increased flame quenching area resulting from smaller combustion chamber clearance distances

Hence, combustion analysis was completed to quantify combustion effects for varying CR and fuel delivery modes over the engine speed range.
BMEP (kPa)

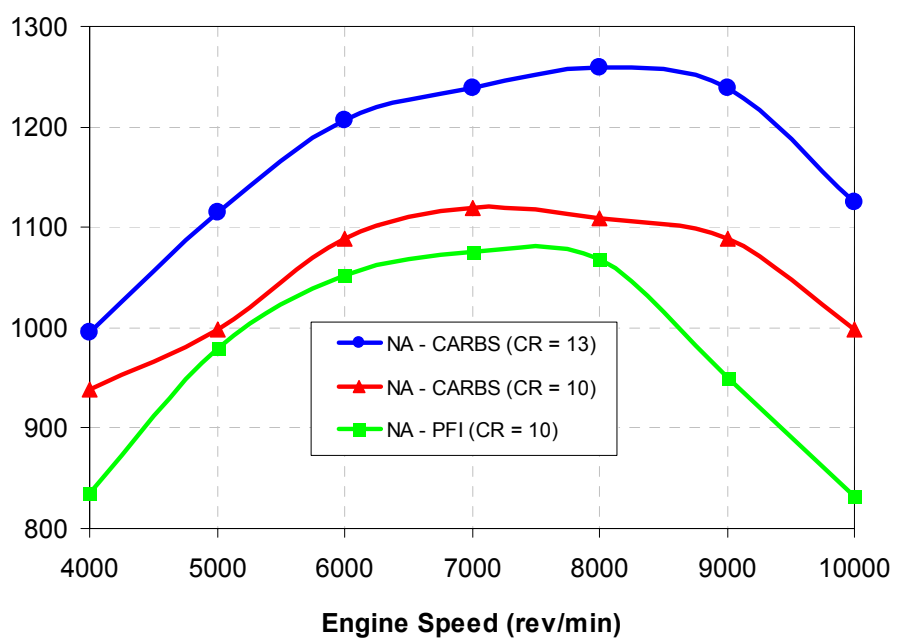

BSFC (g/kWh) $\eta_{\mathrm{TH}}(\%)$

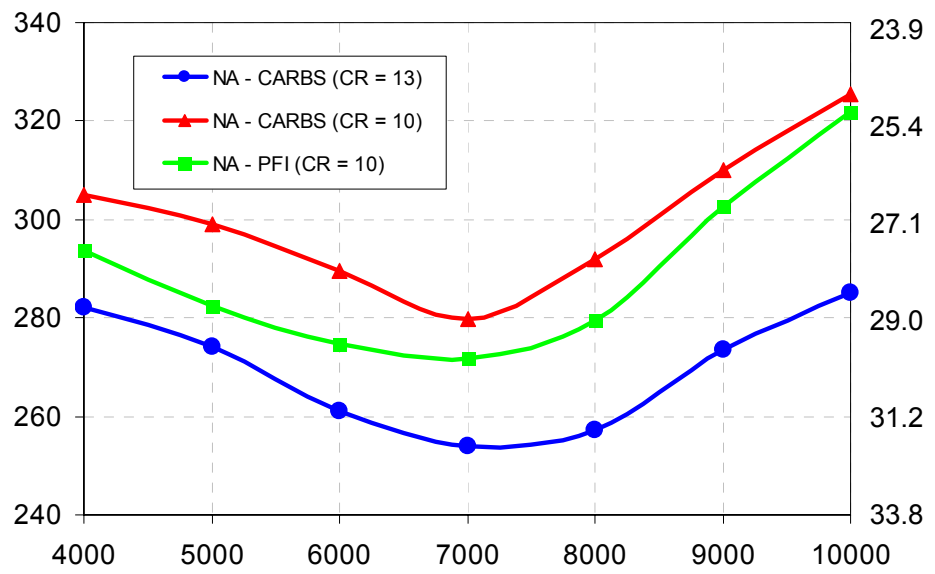

Engine Speed (rev/min)

HC Mole Concentrations (ppm $\mathrm{C}_{6}$ )

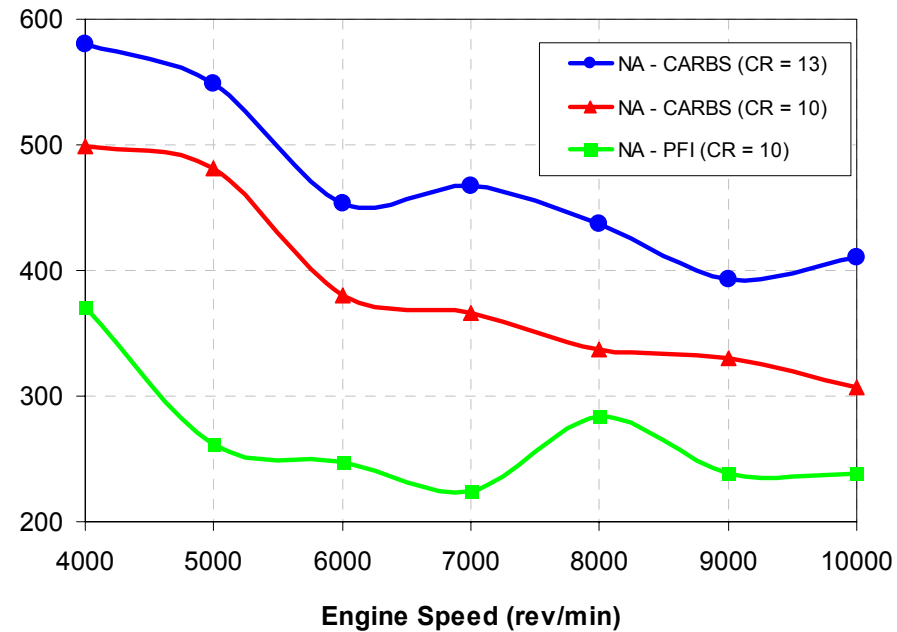

Figure 12: Performance, efficiency and emission effects for varying $\mathrm{CRs}$ and fuel delivery modes. WOT (100 kPa MAP), $\lambda$ $=0.9 \pm 0.02$, MBT spark timing. (Top): BMEP. (Middle): BSFC and $\eta_{\mathrm{TH}}$. (Lower): Engine out HC mole concentrations. 
Combustion analysis was completed using E-CoBRA (Experimental Combustion Burn Rate Analysis) [46], a two-zone quasi dimensional model developed and validated by one of the authors. E-CoBRA was applied to the experimental cylinder pressure data, enabling flame speed, mass fraction burn (MFB), mass burn rate (MBR) and other combustion parameters to be estimated.

Figure 13 presents varying MFB durations in CA and time domains versus engine speed. The $0-10 \%$ MFB duration indicates the initial growth period to a fully developed flame, while the $10-90 \%$ is indicative of the main energy release phase and usually comprises the last $30 \%$ of flame travel. MFB results are computed using the Rassweiler and Withrow method [48-50], which assumes all fuel is consumed (MFB=1).

The effect of engine speed on combustion can be seen in Figure 13. Increasing engine speeds results in a decrease in the time taken to consume the mass fraction. Hence, doubling the engine speed does not double the burn duration in CA degrees. This effect is caused by an increase in turbulence levels, which promote faster flame speeds and hence faster burning rates [7]. Hence the turbulent to laminar flame speed ratio $\left(F S R=S_{T} / S_{L}\right)$ increases for rising engine speeds, with calculated peak flame speeds exceeding $40 \mathrm{~m} / \mathrm{s}$ at maximum engine speeds. Note: this is not the apparent turbulent flame speed, but the turbulent flame speed with respect to the unburned gas velocity at the flame front.

The results for the initial burn fraction $(0-10 \%)$ in the upper diagram of Figure 13 show similar combustion durations over the engine speed range across both fuel delivery modes for equal $C R$. At the higher $C R$, the initial burn rate decreases by $3-5^{\circ} \mathrm{CA}$ corresponding to spark timing reductions (Figure 6 ) across all engine speeds for any given mode. The faster initial burn rates for the higher CR correspond to a temperature increase at the point of ignition, resulting from the higher pressure at ignition. This results in faster laminar flame speeds, which leads to faster flame development.

Conversely for the main burning phase $(10-90 \%)$ in the middle diagram of Figure 13, the higher CR results in reduced burning rates. The reduced burning rates are caused by a combination of factors, which include:

$>$ The higher surface to volume ratio, which leads to higher heat losses to the more proximate surfaces and hence reduced flame speed

$>$ The reduced turbulent length scale in the more constrained cylinder volume around TDC

$>$ The retarded spark timing, which causes the last part of the burn to occur in a larger cylinder volume. This leads to reduced late-in-cycle pressures and temperatures, which slow the flame propagation

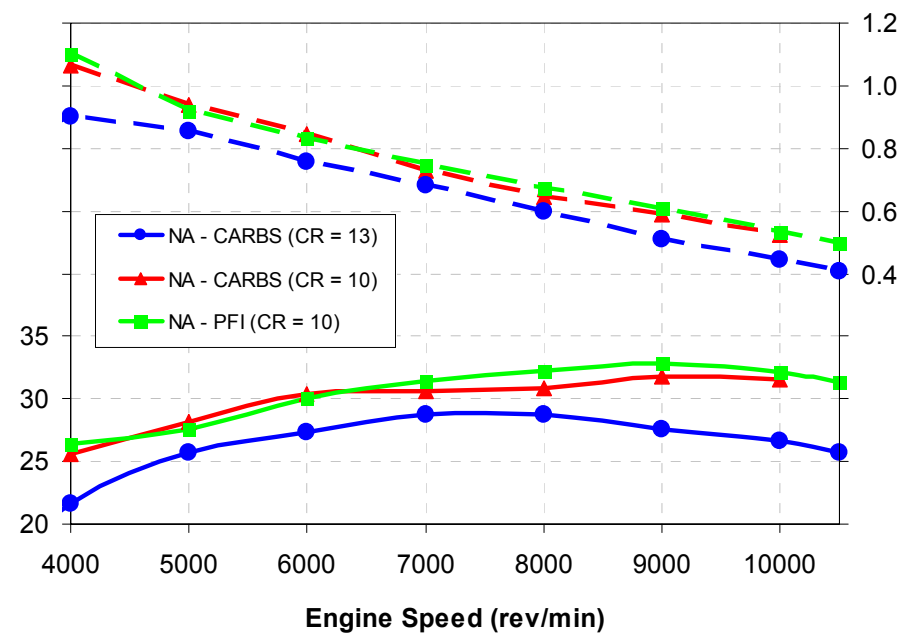

$10-90 \%$ MFB (CAD)

$10-90 \%$ MFB (ms)

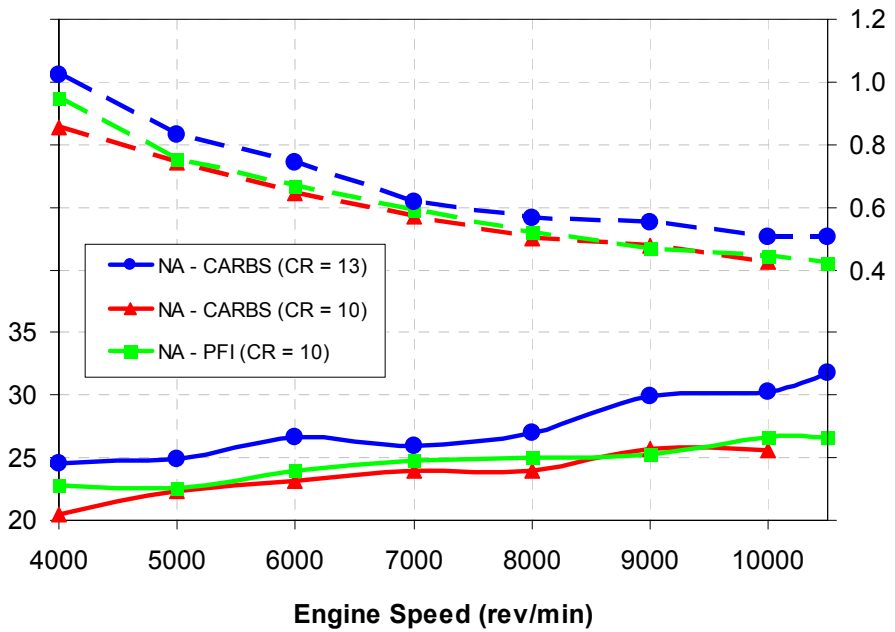

$0-90 \%$ MFB (CAD)

$0-90 \%$ MFB (ms)

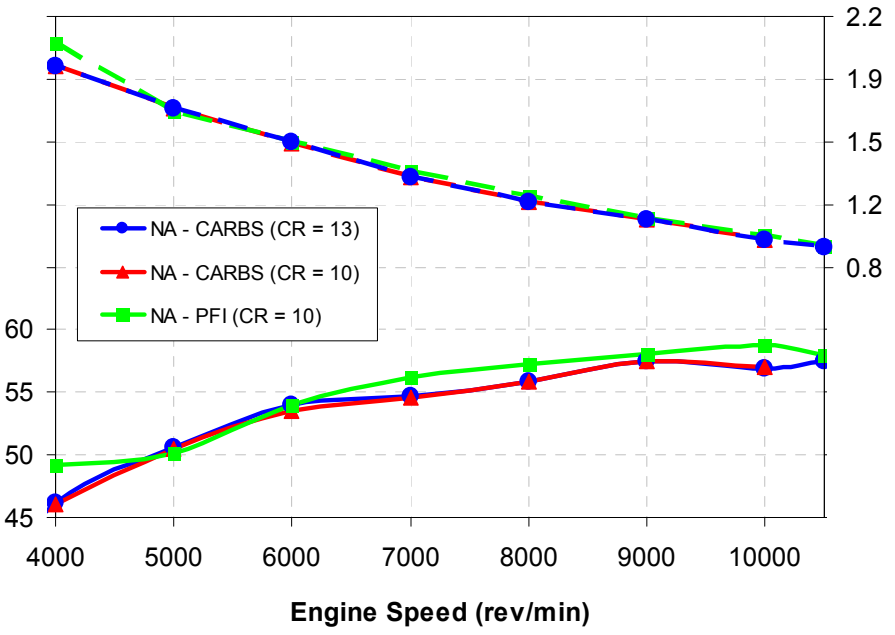

Figure 13: Combustion burn duration effects for varying CRs and fuel delivery modes. WOT (100 kPa MAP), $\lambda=0.9 \pm 0.02$, MBT spark timing. (Top): 0-10\% MFB. (Middle): $10-90 \%$ MFB. (Lower): 0-90\% MFB. 
There are also secondary effects which slow the main $10-90 \%$ burning phase. The higher peak pressures due to the increased CR cause dissociation effects, corresponding to the higher peak cycle temperatures. Consequently, the amount of dissociated $\mathrm{CO}_{2}$ (largely to $\mathrm{CO}$ ) and $\mathrm{H}_{2} \mathrm{O}$ (largely to $\mathrm{H}_{2}$ ) increases. This reduces the temperature from that expected without dissociation, reducing the laminar flame speed $\left(\mathrm{S}_{\mathrm{L}}\right)$ and consequently the turbulent flame speed $\left(\mathrm{S}_{\mathrm{T}}\right)$, which increases the burn duration. A further consequence to this is that combustion goes to completion later in the cycle. The late-in-cycle energy release results in less piston work or indicated mean effective pressure (IMEP) than could have been achieved if the mixture was immediately consumed by the flame.

Considering the various effects present during the initial and main phases of combustion, the total burn times (0$90 \%$ ) show almost no variation with $\mathrm{CR}$ as displayed in the lower diagram of Figure 13. The effect of the faster initial burn and slower later burn phases for the increased CR can be seen in the plot of MFB versus MBR in Figure 14.

Comparing carburetion and PFI, the initial and total burn durations show little variation between both modes. This corresponds to similar MBT spark timing results (Figure 6) across both modes of fuel delivery, supporting the concept of a similar mixture distribution and hence AFR gradient within the combustion chamber.

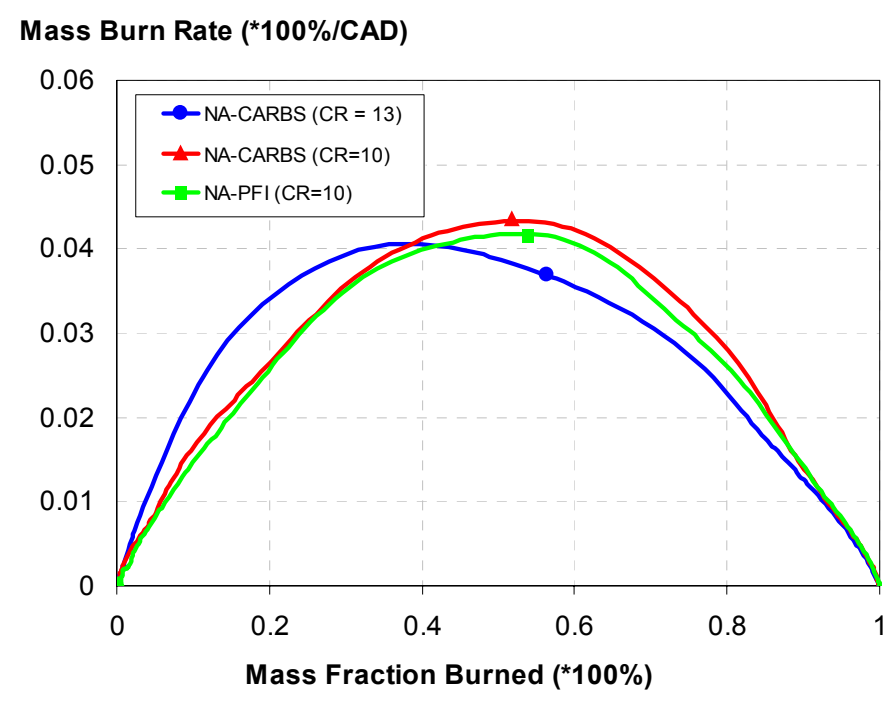

Figure 14: $M F B$ versus MBR for varying CRs and fuel delivery modes. $10000 \mathrm{rev} / \mathrm{min}$, WOT (100 $\mathrm{kPa} \mathrm{MAP}), \lambda=0.9 \pm 0.02$, MBT spark timing.

\section{CONCLUSIONS}

This paper compares the performance, efficiency, emissions and combustion parameters of a prototype two cylinder $430 \mathrm{~cm}^{3} \mathrm{SI}$ engine. Experiments were completed over a range of CRs ranging from 9-13 for both carburetion and PFI fuel delivery systems. Results showed the potential for engine operation at a CR exceeding 13. The high CR achieved for this particular small engine is attributed to the physical size reduction, particularly the reduced bore diameter and fast burn combustion chamber. This resulted in engine speed increases together with end-gas volume reductions around the periphery of the chamber, allowing CR and/or MAP values to be increased before exceeding the DL. This enabled the engine to achieve $37 \% \eta_{\mathrm{TH}}$ and 13 bar BMEP.

When altering the CR, experimental results showed similar order effects on performance, efficiency and emissions when compared to larger bore engines. The test engine's BMEP, $\eta_{\mathrm{TH}}$ and $\mathrm{CO}_{2}$ benefits were also found to have the potential to exceed typical larger bore engines found in passenger vehicles. However, this was only possible after CR optimization, which compensated for the higher levels of dissociation, friction and heat losses associated with the smaller cylinder capacity.

When comparing carburetion to PFI, results show equal performance potential between both modes of fuel delivery. However, a 3\% relative improvement in peak $\eta_{\mathrm{TH}}$ was observed with $\mathrm{PFI}$ due to the improved mixture homogeneity, as confirmed by the $\mathrm{HC}$ emissions. This improvement in $\eta_{\mathrm{TH}}$ increased with decreasing engine speed and load. In addition, reductions in PFI $\mathrm{CO}_{2}$ emissions showed similar trends to $\eta_{\mathrm{TH}}$ findings. However, $\mathrm{HC}$ emissions were shown to be the most significant difference between both modes of fuel delivery, with a reduction in the order of $20 \%$ at WOT when implementing PFI. These performance, efficiency and emission results confirm previous findings and are factors contributing to PFI's universal adoption over carburetion.

Combustion results indicate that the fuel delivery system has little effect on burn rates. However, CR increases result in faster initial burn rates, which produce higher IMEP. Additionally, increases in engine speed do not linearly correlate with combustion duration, with increasing turbulence levels promoting faster flame speeds and hence faster burning rates. Peak flame speeds exceeding $40 \mathrm{~m} / \mathrm{s}$ were recorded at 10500 $\mathrm{rev} / \mathrm{min}$.

The future development of smaller engines for passenger vehicles is addressed in this paper, as engine downsizing grows in popularity due to rising oil prices and recent greenhouse concerns. The results presented have significant relevance to manufacturers who continue to strive for performance and efficiency benefits while meeting legislative pollutant emission standards. 


\section{ACKNOWLEDGMENTS}

The authors are thankful for the patience, support and understanding of family and friends who underlying made the publishing of this paper possible in their unique way. The team is also grateful, to all academic, postgraduate and technical staff involved in this project.

To the generous sponsors that made the UniMelb 'WATTARD' engine possible, we offer our sincere thanks for supporting the excellent learning activity at the University of Melbourne.

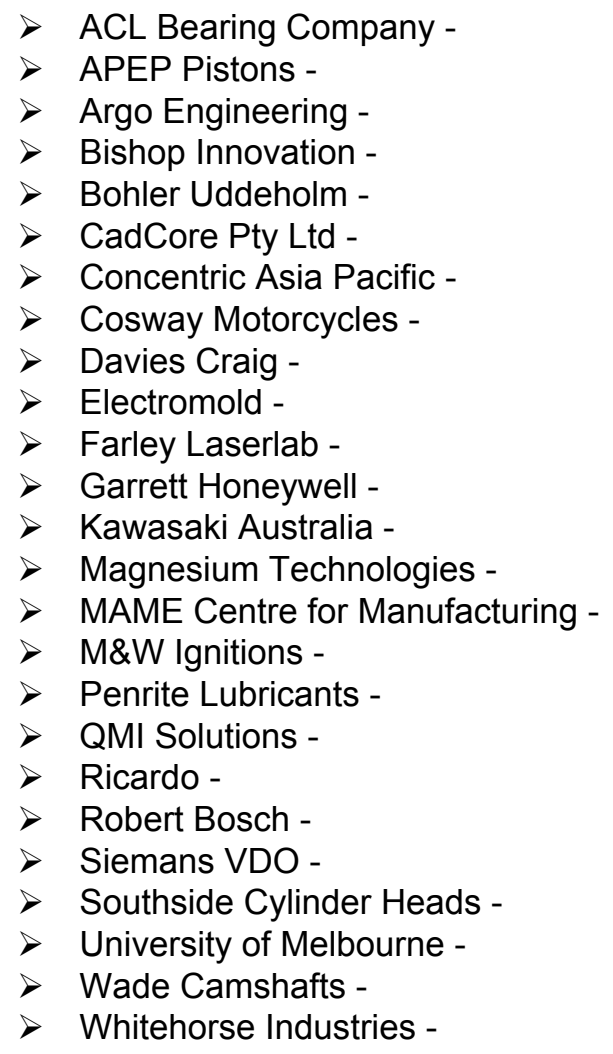

Tas, Australia

Vic, Australia

NSW, Australia

NSW, Australia

Vic, Australia

Vic, Australia

SA, Australia

Vic, Australia

Vic, Australia

Vic, Australia

Vic, Australia

NSW, Australia

NSW, Australia

Vic, Australia

Vic, Australia

NSW, Australia

Vic, Australia

QId, Australia

Sussex, UK

Vic, Australia

Vic, Australia

Vic, Australia

Vic, Australia

Vic, Australia

Vic, Australia
IMEP

IVC

IVO

KA

$\mathrm{KL}$

MAP manifold absolute pressure

MBT maximum brake torque

MFB mass fraction burn

PFI port fuel injection

NA normally aspirated

$\mathrm{PL}$ performance limit

RON research octane number

SI spark ignited

SLS selective laser sintering

ST spark timing

$S_{L} \quad$ laminar flame speed

$\mathrm{S}_{\mathrm{T}} \quad$ turbulent flame speed

TWC three-way catalyst

VVT variable valve timing

WOT wide open throttle

$\eta_{\mathrm{TH}} \quad$ brake thermal efficiency

$\eta_{\text {NOL }} \quad$ volumetric efficiency

$\lambda \quad$ lambda

\section{REFERENCES}

1. LAKE, T., STOKES, J., MURPHY, R., OSBORNE, R. and SCHAMEL, A., 'Turbocharging Concepts for Downsized DI Gasoline Engines', SAE paper 200401-0036. (2004)

2. LECOINTE, B. and MONNIER, G., 'Downsizing a Gasoline Engine Using Turbocharging with Direct Injection', SAE paper 2003-01-0542. (2003)

3. PETITJEAN, D., BERNARDINI, L., MIDDLEMASS, C. and SHAHED, S.M., 'Advanced Gasoline Engine Turbocharging Technology for Fuel Economy Improvements', SAE paper 2004-01-0988. (2004)

4. ATTARD, W.P., 'Exploring the Limits of Spark Ignited Small Engines', Current Ph.D. Thesis, Mech. Eng. Dept., Univ. of Melbourne. (2007)

5. ATTARD, W.P., WATSON, H.C. and KONIDARIS, S., 'Comparing the Performance and Limitations of a Downsized Formula SAE Engine in Normally Aspirated, Supercharged and Turbocharged Modes', SAE paper 2006-32-0072. (2006)

6. DONGHEE, H., SEUNG, K.H. and BONG-HOON, $\mathrm{H}$., 'Development of 2.0L Turbocharged DISI Engine for Downsizing Application', SAE paper 2007-010259. (2007)

7. HEYWOOD, J., 'Internal Combustion Engine Fundamentals', ISBN 007028637X. (1988)

8. TAYLOR, C.F., 'The Internal Combustion Engine in Theory and Practice', Vol. 1 and 2, ISBN 0262700271. (1977)

9. EDISON, M.H., 'The Influence of Compression Ratio and Dissociation on Ideal Otto Cycle Engine 
Thermal Efficiency', SAE Prog. in Technology, vol. 7, pp.49-64. (1964)

10. EDISON, M.H. and TAYLOR, C.F., 'The Limits of Engine Performance-Comparison of Actual and Theoretical Cycles', vol. 7, pp.65-81. (1964)

11. McGEE, J.M., CURTIS, E.W., RUSS, S.G. and LAVOIE, G.A., 'The Effects of Port Fuel Injection Timing and Targeting on Fuel Preparation Relative to a Pre-Vaporized System', SAE paper 2000-012834. (2000)

12. SALAZAR, V. and GHANDHI, J.B., 'Liquid Fuel Effects on the Unburned Hydrocarbon Emissions of a Small Engine', SAE paper 2006-32-0033. (2006)

13. HEISLER, H., 'Advanced Engine Technology', ISBN 1560917342. (1995)

14. ATTARD, W.P. and WATSON, H.C., 'Development of a 430cc Constant Power Engine for FSAE Competition', SAE paper 2006-01-0745. (2006)

15. ATTARD, W.P., WATSON, H.C. and KONIDARIS, S., 'Highly Turbocharging a Restricted Two Cylinder Small Engine - Turbocharger Development', SAE paper 2007-01-1567. (2007)

16. ATTARD, W.P., WATSON, H.C. and STRYKER, P., 'Design and Development of a Gasketless Cylinder Head/Block Interface for an Open Deck, Multi Cylinder, Highly Turbocharged Small Engine', SAE paper 2006-32-0036. (2006)

17. ATTARD, W.P., WATSON, H.C. and KONIDARIS, S., 'Highly Turbocharging a Restricted, Odd Fire, Two Cylinder Small Engine - Design, Lubrication, Tuning and Control', SAE paper 2006-01-3637. (2006)

18. CAIRNS, A., BLAXILL, H., IRLAM, A., Exhaust Gas Recirculation for Improved Part and Full Load Fuel Economy in a Turbocharged Gasoline Engine', SAE paper 2006-01-0047. (2006)

19. ROTHE, M., HEIDENREICH, T., SPICHER, U. and SCHUBERT, A., 'Knock Behavior of SI Engines: Thermodynamic Analysis of Knock Onset Locations and Knock Intensities', SAE paper 2006-01-0225. (2006)

20. OTOBE, Y., GOTO, O., MIYANO, H., KAWAMOTO, M., AOKI, A. and OGAWA, T., 'Honda Formula 1 Turbocharged V6 1.5 liter Engine', SAE paper 890877. (1989)

21. NAKAMURA, Y., 'Small High Speed, High Performance Gasoline Engine', SAE paper 640664. (1983)

22. http://www.ford.com.au

23. http://www.holden.com.au

24. BORETTI, A.A., JIN, S.H., ZAKIS, G., BREAR, M.J., ATTARD, W.P., WATSON, H.C., CARLISLE, H. and BRYCE, W., 'Experimental and Theoretical Study of an Air Assisted Fuel Injector for a D.I.S.I. Engine', SAE paper 2007-01-1415. (2007)
25. BORETTI, A.A., JIN, S.H., ZAKIS, G., BREAR, M.J., ATTARD, W.P., WATSON, H.C., CARLISLE, H. and BRYCE, W., 'Experimental and Theoretical Study of a Direct Injection Spark Ignition Engine', SAE paper 2007-01-1419. (2007)

26. MEHRANI, P., 'Knocking in a HAJI Engine', Current Ph.D. Thesis, Mech.Eng. Dept, Univ. of Melbourne. (2007)

27. Automotive Engineering International, 'Traveling the Long Road to Gasoline Direct Injection', SAE International, June. (2006)

28. ROSENKRANZ, H.G., WATSON, H.C., BRYCE, W. and LEWIS, A. 'Driveability fuel consumption and emissions of 1.3 litre turbocharged spark ignition engine developed as a replacement for a 2 litre normally aspirated engine.' Proc. I.Mech.E., C118/86:139-150 pp. (1986)

29. GERTY, M. and HEYWOOD, J. B., 'An Investigation of Gasoline Engine Knock Limited Performance and the Effects of Hydrogen Enhancement', SAE paper 2006-01-0228. (2006)

30. KLEEBERG, H., TOMAZIC, D., LANG, O. and HABERMANN, K., 'Future Potential and Development Methods for High Output Turbocharged Direct Injected Gasoline Engines', SAE paper 2006-01-0046. (2006)

31. WATSON, H.C., MILKINS, E.E., ROBERTS, K. and BRYCE, W., 'Turbocharging for Fuel Efficiency', SAE paper 830014. (1983)

32. THRING, R.H. and OVERTON, M.T., 'Gasoline Engine Combustion - The High Ratio Compact Chamber', SAE paper 820166. (1982)

33. CARIS, D.F. and NELSON, E.E., 'A New Look at High Compression Ratio Engines', SAE trans., vol. 67, pp. 112-124. (1959)

34. KERLEY, R.V. and THURSTON, K.W., 'The Indicated Performance of Otto-Cycle Engines', SAE trans., vol. 70, pp. 5-30. (1962)

35. MURANAKA, S., TAKAHI, Y. and ISHIDA, T., 'Factors Limiting the Improvement in Thermal Efficiency of S.I. Engine at Higher Compression Ratio', SAE paper 870548. (1987)

36. BAKER, P.A., 'LPG: A Comparison of Multipoint Liquid and Gaseous Phase Injection', Ph.D. Thesis, Mech.Eng. Dept, Univ. of Melbourne. (2007)

37. KHAN, M., 'LPG Throttle Body Injection for Enhanced Air-Fuel Mixing, Reduced Emissions Exploring and Improved Efficiency', M.Eng. Thesis, Mech.Eng. Dept, Univ. of Melbourne. (2007)

38. WATSON, H.C. and MILKINS, E.E., 'Cylinder Head Design', Modern engine developments Lecture 7246/1, University of Melbourne. (1972)

39. EDGAR, J., ' $21^{\text {st }}$ Century Performance', ISBN 0947216901. (2000) 
40. YAGI, S., ISHIZUYA, A. and FUJII, I., 'Research and Development of High Speed, High Performance, Small Displacement Honda Engines', SAE paper 700122. (1970)

41. KONIDARIS, S. and STICKNEY, S., 'Optimizing a Modified Kawasaki GPZ500S', Undergraduate Thesis, Mech.Eng. Dept, Univ. of Melbourne. (2004)

42. KHAN, M., WATSON, H.C., BAKER, P.A., LIEW, G. and JOHNSTON, D., 'SI Engine Lean-Limit Extension Through LPG Throttle-Body Injection for Low CO2 and NOx', SAE paper 2006-01-0495. (2006)

43. 'Motor Vehicle Emission Regulations and Fuel Specifications', Part 1, Summary and annual 1997/1998 update, Brussek CONCAWE, Report no. 9/98. (1998)

44. STONE, R., 'Introduction to Internal Combustion Engines', ISBN 0768004950. (1999)

45. FRAIDL, G.K., 'Spray Quality of Mixture Preparation Systems', EAEC Int. Conf. on New Developments in Powertrain and Chassis Engineering, Strasbourg, Vol. 1, pp 232-246. (1987)

46. HAMORI, F., 'Exploring the Limits of Hydrogen Assisted Jet Ignition', Ph.D. Thesis, Mech.Eng. Dept, Univ. of Melbourne. (2006)

47. QUADER, A.A, KIRWAN, J.E. and GRIEVE, M.J., 'Engine Performance and Emissions Near the Dilute Limit with Hydrogen Enrichment Using an On-Board Reforming Strategy', SAE paper 2003-01-1356. (2003)

48. BRUNT, M.F.J. and ERNTAGE, A.L., 'Evaluation of Burn Rate Routines and Analysis Errors', SAE paper 970037. (1997)

49. RANDOLPH, A.L., 'Cylinder-Pressure-Based Combustion Analysis in Race Engines', SAE paper 942487. (1994)

50. RASSWEILER, G.M. and WITHROW, L., 'Motion Pictures of Engine Flames Correlated with Pressure Cards', SAE trans. Vol. 42. (1938)

\section{CONTACT}

William Attard

Thermofluids Group

Department of Mechanical Engineering

University of Melbourne,

Victoria, Australia, 3010

Email: william_attard@hotmail.com

Prof. Harry Watson

Head Thermofluids Group

Department of Mechanical Engineering

University of Melbourne

Victoria, Australia, 3010

Email: harrycw@unimelb.edu.au 


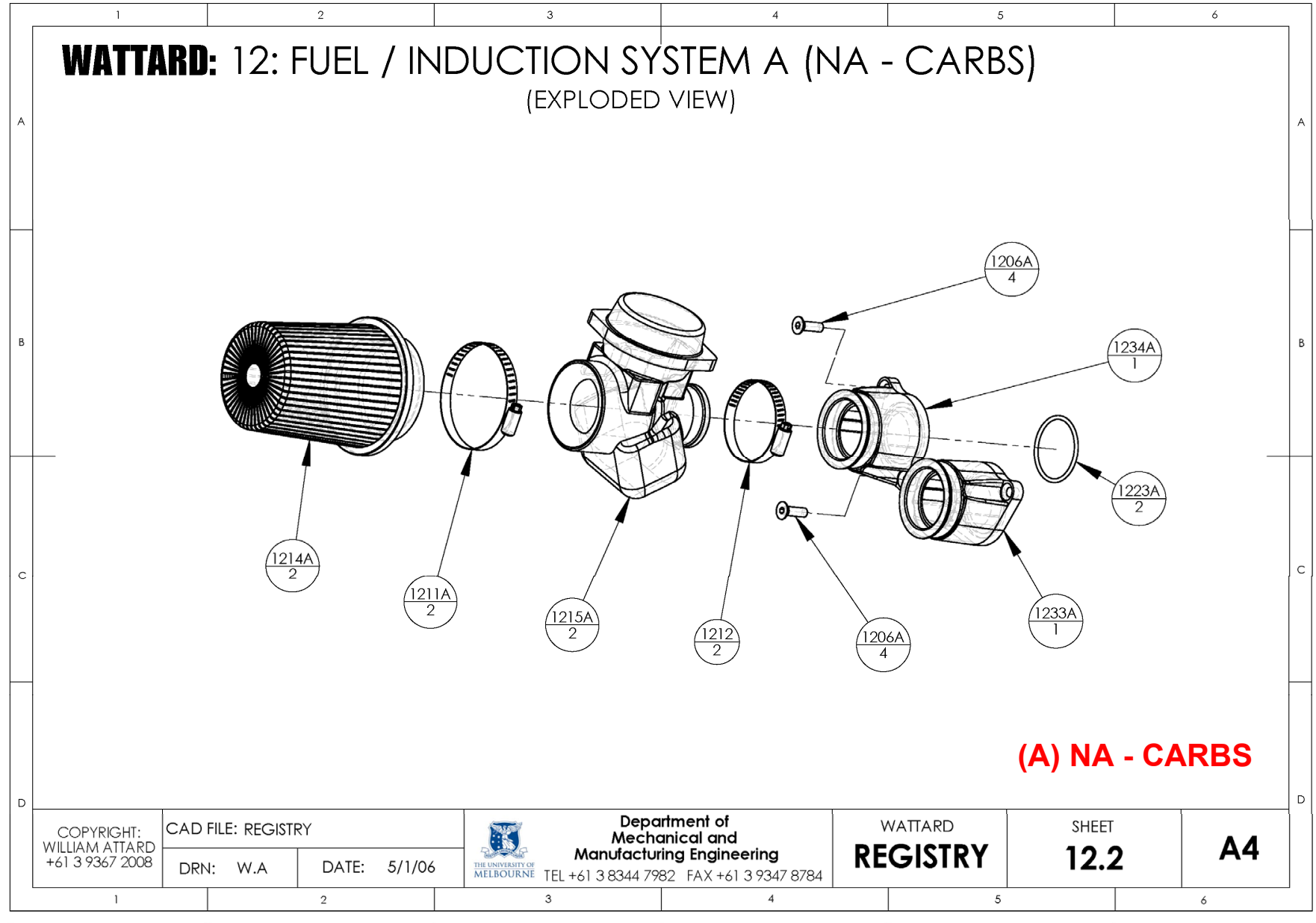

WATTARD: 12: FUEL / INDUCTION SYSTEM B (NA - EFI) (EXPLODED VIEW)

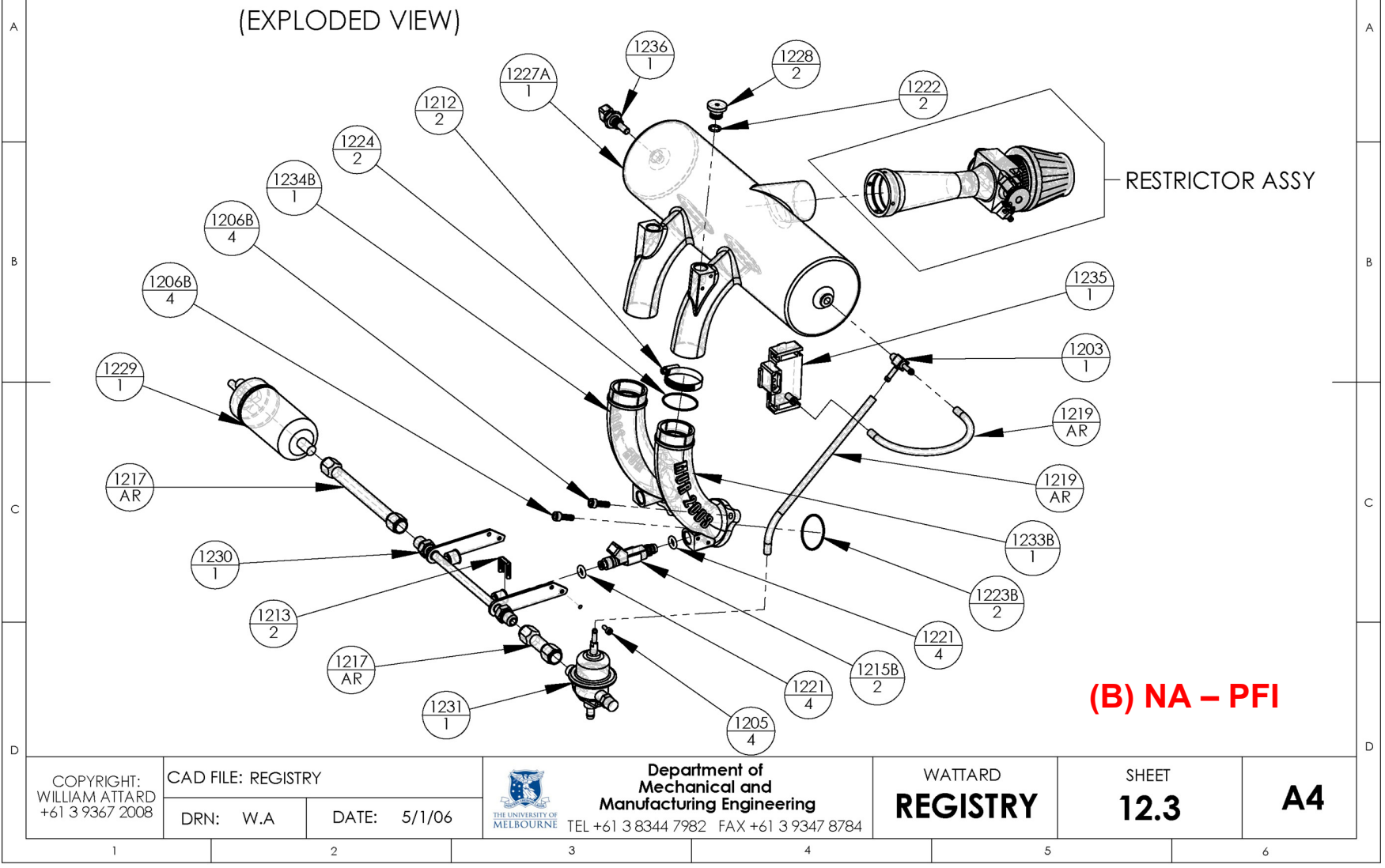




\section{University Library}

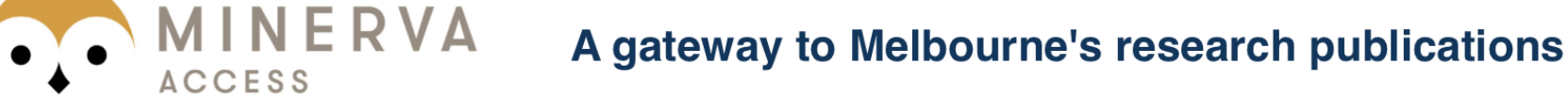

Minerva Access is the Institutional Repository of The University of Melbourne

Author/s:

Attard, William;Konidaris, Steven;Hamori, Ferenc;Toulson, Elisa;Watson, Harry

Title:

Compression ratio effects on performance, efficiency, emissions and combustion in a carbureted and PFI small engine

Date:

2007

Citation:

Attard, W., Konidaris, S., Hamori, F., Toulson, E., \& Watson, H. (2007). Compression ratio effects on performance, efficiency, emissions and combustion in a carbureted and PFI small engine. In, Proceedings, SAE International APAC Conference, Hollywood, CA, USA.

Publication Status:

Published

Persistent Link:

http://hdl.handle.net/11343/34816 